MIMBAR

JURNAL PENELITIAN SOSIAL DAN POLITIK

Desember 2018

ISSN : 2252-5270 \& E-ISSN : 2620-6056

Volume 7 No. 2

\title{
PENGARUH KUALITAS SUMBER DAYA MANUSIA DAN BUDAYA ORGANISASI TERHADAP RESPONSIVITAS PELAYANAN BIROKRASI DI KELURAHAN KAMPUNG KELAWI KECAMATAN SUNGAI SERUT KOTA BENGKULU
}

\author{
Oleh: \\ Ridianto $^{1 *}$, Ovita Charolina ${ }^{2}$ \\ *Email : stia.radianto@gmail.com
}

\begin{abstract}
ABSTRAKS
Penelitian ini bertujuan menganalisis pengaruh kualitas sumber daya manusia yang terdiri dari indikator profesionalisme aparat, tanggung jawab, kreatifitas dan budaya organisasi yang terdiri dari indikator sikap yang dimiliki, nilai-nilai dominan, iklim, organisasi terhadap responsivitas pelayanan birokrasi di kelurahan Kampung Kelawi Kota Bengkulu. Penelitian ini dilaksanakan dengan metode survei eksplanatori pada aparat dan masyarakat kelurahan Kampung Kelawi. Pengumpulan data dilakukan dengan teknis observasi, kuesioner dan dokumentasi terhadap responden. Hasil pengumpulan data selanjutnya dianalisis menggunakan tabulasi silang, korelasi product moment, dan analisa regresi. Dari hasil penelitian menunjukkan adanya signifikansi yang kuat dari sumber daya manusia dan budaya organisasi terhadap responsivitas pelayanan birokrasi di kelurahan Kampung Kelawi Kota Bengkulu. Dari dua variabel menunjukkan bahwa keduanya mempunyai tingkat keeratan hubungan terhadap responsivitas pelayanan. Oleh karena itu agar responsivitas pemerintah dapat berjalan efektif maka perlu ditingkatkan kualitas sumber daya manusia dan diefektifkan budaya organisasi sehingga dapat tercapai responsivitas pelayanan birokrasi yang dapat memuaskan keinginan masyarakat.
\end{abstract}

Kata Kunci : Sumber daya manusia, budaya organisasi, responsivitas pelayanan birokrasi

\begin{abstract}
This study analyzes the quality of human resources which consists of indicators of apparatus professionalism, accountability, creativity and organizational culture which consist of required assessment indicators, dominant values, conservation, organization towards responsiveness of bureaucratic services in Kelawi Kelurahan, Bengkulu City. This research was carried out by explanatory survey method in the apparatus and community of Kelawi Village. Data collection is done by observation, questionnaire and documentation techniques to respondents. The results of data collection are then analyzed using cross tabulation, product moments, regression analysis. From the results of the study showed a strong significance of human resources and organizational culture on the responsiveness of bureaucratic services in the Kelawi Kelurahan, Bengkulu City. Of the two variables that indicate the level of participation in the relationship to service responsiveness. Therefore, in order for government responsiveness to be effective, it is necessary to improve the quality of human resources and streamline organizational culture so that it can increase the responsiveness of bureaucratic services that can satisfy people's needs.
\end{abstract}

Keywords: Human resources, organizational culture, responsiveness of bureaucratic services

\footnotetext{
${ }^{1}$ Dosen Sekolah Tinggi Ilmu Administrasi (STIA) Bengkulu

${ }^{2}$ Dosen Sekolah Tinggi Ilmu Administrasi (STIA) Bengkulu
} 
MIMBAR

JURNAL PENELITIAN SOSIAL DAN POLITIK Desember $2018 \quad$ ISSN : 2252-5270 \& E-ISSN : 2620-6056

\section{A. Pendahuluan}

Salah satu tuntutan publik untuk perbaikan kehidupan politik di Indonesia adalah tuntutan pemberian otonomi yang luas kepada daerah kabupaten dan kota. Kemampuan dari suatu 2 atern pelayanan publik dalam merespon dinamika yang terjadi dalam masyarakat secara tepat dan efisien akan sangat ditentukan oleh bagaimana misi dari birokrasi dipahami dan dijadikan sebagai basis dan 2 aternal dalam pengambilan kebijakan oleh birokrasi itu. Ketidakjelasan misi akan menyebabkan bias pada pelayanan publik.

Dalam konteks pelaksanaan otonomi daerah perlu alternatif dan sekaligus melepaskan makna hegemoni paham teknokrasi yang masih harus dirasakan sekarang. Pemerintah yang membuat konsep otonomi daerah sulit melepaskan orientasi pembangunan dan kepercayaan pada peran 2 atern sebagai mesin pembangunan (pembangunan, oleh 2 atern), dengan satu tawaran 2aternal baru, maka otonomi daerah tidak semata-mata menggali PAD tetapi juga soal akses keterlibatan masyarakat, fasilitas perkembangan ekonomi swasta oleh penegasan azas good governance (partisipasi, transparasi, dan akuntabilitas) dalam penyelenggaraan pemerintahan. Demikian halnya pada tingkat pemerintahan yang terendah yaitu kelurahan/desa.

Dalam kenyataan pelayanan yang diberikan oleh suatu organisasi pemerintah pusat kepada daerah propinsi tidak harus semua dilaksanakan, karena pelayanan diberikan sepanjang hal itu memang dibutuhkan dan membawa kemaslahatan bagi masyarakat, demikian pula kewenangan yang diberikan pemerintah daerah propinsi kepada pemerintah daerah kabupaten sampai kepada tingkat kelurahan/desa. Dalam situasi herarkhis yang sangat tinggi menyebabkan pola pelayanan dari masingmasing daerah atau kelurahan akan sangat bervariasi tergantung pada kemampuan yang ada di daerah. Dengan kata lain kegiatan pelayanan dan perlindungan kepada masyarakat akan diberikan dalam batas kemampuan yang dimiliki oleh pemerintah dibawahnya atau kelurahan.

Dalam rangka meneliti birokrasi pelayanan pemerintah kelurahan, penulis akan meneliti tentang responsivitas kinerja
Pemerintah Kelurahan di Kelurahan Kampung Kelawi Kecamatan Sungai Serut yang dipilih secara proporsive random sampling area.Buruknya pelayanan yang demikian dapat menggambarkan kinerja birokrasi dalam melayani masyarakat yang tidak memperhatikan responsivitas, responsibilitas dan akuntabilitas.Tetapi melihat konfigurasi personal yang ada dan keadaan yang berkenaan dengan birokratisasi yang ada penulis dapat mengidentifikasikan adanya sumber daya dan budaya organisasi. Sumber daya manusia yang kurang memadai serta struktur birokrasi yang ada diperkirakan akan berpengaruh terhadap kinerja pelayanan yang dijalaskan. Sumber daya manusia memiliki kedekatan dengan pendidikan. Seperti diutarakan oleh (Dwiyanto, 2013) beberapa kabupaten dan kota menyadari bahwa otonomi daerah memerlukan kemampuan aparatur yang lebih baik dan melakukan investasi pada aparaturnya dengan memberikan beasiswa untuk menempuh jenjang pendidikan yang lebih tinggi. Sekalipun pendapat ini tidak secara langsung akan mempengaruhi kinerja tetapi dapat diramalkan bahwa pendidikan yang tinggi cenderung membuka wawasan yang lebih luas akibatnya dapat membentuk kinerja yang lebih baik dalam pekerjaannya.

Selain sumber daya adalah patern budaya organisasi. Aspek budaya organisasi diperkirakan berpengaruh terhadap kinerja pelayanan birokrasi. Budaya organisasi merupakan suatu keadaan lingkungan dalam suatu organisasi yang berkaitan dengan suatu kesatuan asumsi-asumsi, kepercayaankepercayaan, nilai-nilai yang dibawa kemudian diintegrasikan oleh seluruh anggota organisasi tersebut untuk membimbing mereka dalam melaksanakan fungsinya. Dalam organisasi terjadi transaksi dan kristalisasi yang membentuk budaya yang lain menjadi budaya organisasi. Budaya organisasi sebagaimana dikatakan (Luthan, 2011) dipercaya dapat mempengaruhi responsivitas pelayanan organisasi.

Berdasarkan latar belakang penelitian di atas maka, yang menjadi permasalahan dalam penelitian ini, adalah fenomena kinerja birokrasi pemerintah kelurahan yang berkenaan dengan sumber daya manusia dan budaya organisasi 
Kelurahan Kampung Kelawi Kecamatan Sungai Serut Kota Bengkulu. Bila dirumuskan akan tersusun kalimat sebagai berikut :"Bagaimana tingkat signifikansi sumber daya manusia dan budaya organisasi terhadap responsivitas pelayanan birokrasi di Kelurahan Kampung Kelawi Kota Bengkulu?

\section{B. Metode Penelitian}

Sesuai dengan maksud penelitian yang akan menguji hipotesa, maka metode penelitian yang digunakan adalah metode kuantitatif. Karena penelitian ini adalah penelitian sosial maka tipe penelitian yang digunakan adalah survei eksplanatori. Sesuai dengan topik penelitian ini maka unit analisisnya adalah warga kelurahan Kampung Kelawi, yang terdiri dari perangkat kelurahan, tokoh masyarakat seperti ketua RW, ketua RT, kepala dukuh, tokoh agama, tim penggerak PKK yang ada di Kelurahan Kampung Kelawi Kota Bengkulu.

Jumlah responden yang diambil adalah semua yang mempunyai kriteria sebagai tokoh masyarakat, karena yang tahu perisis seluk beluk permasalahan yang ada di kantor kelurahan Kampung Kelawi, yaitu 92 orang dengan rincian sebagai berikut : Perangkat kelurahan 11 orang, Kepala dukuh 9 orang, Ketua RW 10 orang, Ketua RT 29 orang, Tokoh Agama 4 orang, Tim Penggerak PKK 20 orang, Tokoh Pemuda 9 orang. Pengambilan sampel dari semua kriteria diambil semua dengan cara Disproportional Random Sampling (Sugiyono, 1998).

Setelah data terkumpul, peneliti selanjutnya menganalisis sesuai dengan metode yang diajukan agar data mentah dapat dipahami sekaligus dapat menjawab pertanyaan-pertanyaan yang telah diajukan sebelumnya yaitu dilakukan dengan cara melakukan korelasi antar variabel penelitian antara lain adalah :

1. Korelasi product moment, tujuannya adalah untuk mencari/menghitung berapa besar tingkat keeratan hubungan antara variabel independent dengan variabel pendenden.

2. Koefisien korelasi parsial, tujuannya adalah untuk mengetahui tingkat kemurnian hubungan antara variabel $\mathrm{X}$, terhadap variabel $\mathrm{Y}$ dengan dikontrol oleh variabel $\mathrm{X}_{2}$ atau sebaliknya.
Analisis regresi : tujuannya adalah untuk melakukan prediksi seberapa jauh nilai variabel dependen bila nilai variabel independen dirubah.

\section{Hasil Penelitian}

1. Pengaruh Kualitas Sumber Daya Manusia $\quad\left(\mathrm{X}_{1}\right) \quad$ Terhadap

Responsivitas Pelayanan (Y)

Untuk mengetahui tingkat prediksi variabel $\mathrm{X}_{1}$ dan variabel $\mathrm{Y}$ tersebut digunakan analisa regresi sederhana. Adapun hasil perhitungan tersebut diketahui sebesar 0,708 artinya setiap terjadi perubahan pada variabel kualitas sumber daya manusia $\left(\mathrm{X}_{1}\right)$ sebesar 0,708 maka akan terjadi perubahan pada variabel responsivitas pelayanan birokrasi (Y) sebesar 0,708. Jadi setiap perubahan pada variabel $\mathrm{X}_{1}$ akan diikuti pula perubahan pada variabel $Y$.

Untuk mengetahui berapa besar pengaruh kualitas sumber daya manusia $\left(\mathrm{X}_{1}\right)$ terhadap variabel responsivitas pelayanan birokrasi (Y) digunakan uji t yang hasilnya adalah $\mathrm{t}$ hitung sebesar 9,508. Sedangkan $\mathrm{t}$ tabel dengan tingkat kesalahan 5 persen hasilnya adalah 1,671 sehingga $t$ hitung $(9,508)>\mathrm{t}$ tabel $(1,671)$. Dengan demikian maka Ho ditolak dan Hi diterima. Artinya ada pengaruh yang signifikan antara variabel kualitas sumber daya manusia terhadap variabel responsivitas pelayanan birokrasi.

Dari indikator-indikator yang ada pada variabel sumber daya manusia, yaitu tingkat profesionalisme, tingkat tanggung jawab aparat dan tingkat kreatifitas tidak memiliki kekuatan pengaruh yang sama terhadap variabel responsivitas. Ini dilihat dari banyak jumlah skor pada indikator tersebut, dimana indikator tingkat profesionalisme memiliki total skor sebesar 1.171 sedangkan tingkat tanggung jawab sebesar 1.672 dan tingkat kreatifitas responden memiliki total skor sebesar 1.253. Dari angka-angka tersebut terlihat bahwa profesionalisme memiliki jumlah skor terendah yaitu 1.171 dan yang paling tinggi adalah tingkat tanggung jawab yaitu 1.672. sehingga profesionalisme aparat memiliki pengaruh yang paling lemah terhadap responsivitas pelayanan birokrasi, dengan demikian maka perlu ditinjau kembali agar profesionalisme aparat birokrasi Kelurahan Kampung Kelawi dapat ditingkatkan, 
sehingga tingkat responsivitas pelayanan akan meningkat sesuai dengan yang dikehendaki oleh masyarakat.

2. Pengaruh Budaya Organisasi $\left(\mathrm{X}_{2}\right)$

Terhadap Responsivitas Pelayanan Birokrasi (Y)

Untuk mengetahui tingkat prediksi variabel $\mathrm{X}_{2}$ dan variabel $\mathrm{Y}$ dengan menggunakan analisa regresi sederhana. Adapun hasil perhitungannya diketahui sebesar 0,706. Artinya setiap terjadi perubahan pada variabel budaya organisasi $\left(\mathrm{X}_{2}\right)$ sebesar 0,706 maka akan diikuti dengan perubahan pada variabel responsivitas (Y) pelayanan birokrasi sebesar 0,706. Jadi berubahnya variabel $\mathrm{X}_{2}$ akan diikuti pula dengan berubahnya variabel Y.

Untuk mengetahui berapa besar pengaruh variabel budaya organisasi $\left(\mathrm{X}_{2}\right)$ terhadap variabel responsivitas pelayanan birokrasi (Y) digunakan uji t yang hasilnya adalah 9,326 sedangkan $\mathrm{t}$ tabel dengan tingkat kesalahan sebesar 5 persen hasilnya adalah 1,671 sehingga $t$ hitung $(9,326)>t$ tabel (1,671). Dengan demikian maka menolak Ho dan menerima Hi.Artinya ada pengaruh yang signifikan antara variabel budaya organisasi terhadap variabel responsivitas pelayanan birokrasi.

Dari indikator-indikator yang ada pada variabel budaya organisasi yaitu setiap perilaku yang dimiliki, nilai-nilai dominan, iklim organisasi tidak memiliki kekuatan pengaruh yang sama terhadap tingkat responsivitas pelayanan birokrasi. Ini dilihat dari banyaknya skor pada indikatorindikator tersebut. Indikator sikap perilaku yang dimiliki memiliki total skor sebesar : 1200, indikator nilai-nilai dominan memiliki total skor sebesar : 1262 dan indikator iklim organisasi memiliki total skor : 1238. Dari angka-angka tersebut terlihat bahwa indikator sikap perilaku yang dimiliki menunjukkan angka yang paling rendah 1200, dan yang tertinggi adalah indikator nilai-nilai dominan yaitu : 1262. Artinya indikator sikap perilaku yang dimiliki mempunyai pengaruh yang lemah terhadap responsivitas pelayanan birokrasi. Hal ini perlu ditinjau kembali bagaimana sikap aparat pada waktu melakukan pelayanan pada masyarakat, apakah sikap aparat ramah atau tidak, apakah aparat selalu mengutamakan kepentingan masyarakat, rata-rata responden hanya menjawab dalam kategori sedang, sehingga sikap aparat kurang memuaskan pelayanannya pada masyarakat. Sikap demikian menggambarkan kurang berpengaruh tingkat profesional aparat terhadap responsivitas kinerja birokrasi di Kelurahan Kampung Kelawi.

3. Pengaruh Kualitas Sumber Daya Manusia $\left(\mathrm{X}_{1}\right)$ dan Budaya Organisasi $\left(X_{2}\right)$ Terhadap Responsivitas Pelayanan (Y)

Untuk mengetahui pengaruh variabel kualitas sumber daya manusia $\left(\mathrm{X}_{1}\right)$ dan budaya organisasi $\left(\mathrm{X}_{2}\right)$ secara bersamasama terhadap variabel responsivitas pelayanan birokrasi (Y), digunakan analisa regresi majemuk dengan analisis varian (ANOVA). Adapun hasil perhitungannya adalah sekitar 71,395 ini adalah $\mathrm{F}$ hitung. Untuk mengetahui tingkat signifikan pengaruh variabel $\mathrm{X}_{1}$ dan $\mathrm{X}_{2}$ terhadap $\mathrm{Y}$, dalam tingkat kesalahan 5 persen, $\mathrm{F}$ tabel = 3,44 sehingga $F$ hitung (71.395) $>F$ tabel $(3,44)$. Dengan demikian Ho ditolak dan alternatifnya $\mathrm{Hi}$ diterima. Berarti bahwa $\mathrm{B} \neq$ 0 sehingga ada hubungan fungsional antara variabel responsivitas dan kualitas sumber daya manusia dan varibel budaya organisasi. Artinya variabel responsivitas selalu dipengaruhi oleh variabel sumber daya manusia yang merupakan fungsi tercapainya tingkat responsivitas pelayanan birokrasi di Kelurahan Kampung Kelawi. Semakin tinggi tingkat profesionalisme aparat birokrasi maka semakin tinggi pula responsivitas pelayanan birokrasi di Kelurahan Kampung Kelawi atau semakin besar daya tanggapnya terhadap kebutuhankebutuhan masyarakat. Semakin tinggi tingkat tanggung jawab aparat dalam pelayanan maka akan semakin tinggi pula responsivitas pelayanan birokrasi di Kelurahan Kampung Kelawi. Semakin kreatif aparat dalam memberikan pelayanan maka semakin mampu merespon kebutuhan masyarakat akan pelayanan birokrasi pemerintah kelurahan.

Di samping kualitas sumber daya manusia, budaya organisasi juga berfungsi untuk meningkatkan responsivitas pelayanan birokrasi pemerintah Kelurahan Kampung Kelawi. Semakin positif/baik sikap perilaku aparat, terutama dalam memberikan pelayanan dan mengutamakan kepentingan masyarakat maka akan semakin mampu 
merespon kebutuhan-kebutuhan masyarakat. Semakin baik nilai-nilai dominan yang digambarkan pada sikap loyal, disiplin yang tinggi dan bekerja efektif dan efisien maka akan semakin mampu merespon kebutuhankebutuhan masyarakat. Semakin baik iklim organisasi dalam arti adanya kerjasama yang baik antar aparat, sungguh-sungguh dalam melaksanakan pelayanan, dan mengerti dengan pasti tugas pokok dan fungsinya maka akan semakin mampu merespon kebutuhan-kebutuhan masyarakat di Kelurahan Kampung Kelawi Kota Bengkulu.

\section{Pembahasan}

Berdasarkan hasil penelitian yang dilakukan oleh peneliti dapat dideskripsikan bahwa variabel sumber daya manusia $\left(\mathrm{X}_{1}\right)$ seperti yang disebutkan (Cordozo, 1997) dimana sumber daya manusia terdiri dari beberapa aspek seperti akal, perasaan, keinginan, kemampuan, ketrampilan, pengetahuan, dorongan, daya dan karya,begitu juga dengan variabel budaya organisasi $\left(\mathrm{X}_{2}\right)$ dimana menurut penjelasan (Luthan, 2011) tentang budaya organisasi, didalam suatu organisasi terdapat beberapa aspek sepertinilai, kepercayaan-kepercayaan dan perilaku-perilaku aternali. Kedua variabel inilah yang terdiri dari masingmasing aspeknya memilki signifikansi yang terhadap responsivitas pelayanan.

Seberapa besar signifikansi kedua varibel yakni sumber daya manusia dan budaya organiasasi terhadap responsivitas pelayanan birokrasi dapat dlihat dengan menggunakan hasil uji. Signifikansi sumber daya manusia terhadap responsivitas pelayanan dibuktikan dengan perolehan hasil uji sumber daya manusia dengan nilai uji $(9,326)>$ responsivitas pelayanan dengan nilai uji $(1,671)$, berdasarkan hasil uji tersebut didapat bahwa sumber daya manusia memiliki signifikansi terhadap responsivitas pelayanan. Begitu juga untuk variabel 2 yakni budaya organisasi dengan menggunakan hasil uji nilai, dimana budaya organisasi dengan nilai uji $(9,326)>$ responsivitas pelayanan dengan nilai uji $(1,671)$, berdasarkan perolehan hasil uji tersebut didapat bahwa budaya organisasi yang terdiri dari bebagai aspek memiliki signifikansi terhadap responsivitas pelayanan. Begitu juga dengan perolehan hasil uji kedua variabel secara bersama-sama yakni pengaruh kualitas sumber daya manusia (x1) dan budaya organisasi (x2) terhadap responsivitas pelayanan (y) digunakan hasil uji. Kualitas sumber daya manusia dan budaya organisasi (71.395) > responsivitas pelayanan $(3,44)$, dari perolehan hasil uji tersebut di dapat bahwa adanya hubungan antara kualitas sumber daya manusia dan budaya organisasi terhadap resposivitas pelayanan.

Berdasarkan hasil penelitian yang diperoleh oleh peneliti di Kelurahan Kampung Melayu Kecamatan Sungai Serut Kota Bengkulu dilihat dari hasil skor setiap aspek variabel didapat bahwa adanya signifikansi kualitas sumber daya manusia dan budaya organisasi terhadap responsivitas pelayanan birokrasinya.

\section{E. Kesimpulan dan Saran}

\section{Kesimpulan}

1) Tingkat responsivitas pelayanan birokrasi pemerintah Kelurahan Kampung Kelawi tinggi, terutama pada program pengembangan pelayanan masyarakat, hanya saja masyarakat yang kurang tanggap terhadap apa yang telah dilakukan oleh birokrasi kelurahan. Hal ini disebabkan kurangnya pengetahuan masyarakat akan fungsi birokrasi.

2) Kualitas Sumber daya manusia berpengaruh siginifikan terhadap responsivitas pelayanan birokrasi pemerintahan Kelurahan Kampung Kelawi. Hal ini terbukti bahwa kualitas sumber daya manusia sangat menentukan tingkat responsivitas pelayanan birokrasi. Artinya semakin berkualitas sumber daya manusia maka akan semakin tinggi tingkat responsivitas pelayanan birokrasi pemerintah Kelurahan Kampung Kelawi Kota Bengkulu.

3) Budaya organisasi berpengaruh siginifikan terhadap responsivitas pelayanan birokrasi pemerintahan Kelurahan Kampung Kelawi. Hal ini terbukti bahwa budaya organisasi merupakan pendorong yang positif terhadap responsivitas dalam melayani masyarakat. Artinya semakin positif dan baik budaya organisasi maka akan semakin efektif responsivitas pelayanan birokrasi pemerintah Kelurahan Kampung Kelawi Kota Bengkulu. 
Secara bersama-sama kualitas sumber daya manusia dan budaya organisasi berpengaruh signifikan terhadap responsivitas pelayanan birokrasi pemerintah Kelurahan Kampung Kelawi Kota Bengkulu. Hal ini terbukti bahwa kualitas sumber daya manusia dan budaya organisasi merupakan dua aspek penting dalam terwujudnya responsivitas kinerja kelurahan. Dengan demikian maka, semakin berkualitas sumber daya manusia dan semakin positif budaya organisasi sebagai unsur pendorong keberhasilan, maka akan semakin baik juga responsivitas pelayanan birokrasi pemerintah Kelurahan Kampung Kelawi Kota Bengkulu.

\section{DAFTAR PUSTAKA}

\section{Sumber dari Buku :}

Atep, Adtya, Barata, 2004, Dasar-dasar Pelayanan Prima, Jakarta : PT. Elex Media Komputindo.

Bryson, J. (1995). Perencanaan Strategi Bagi Organisasi Sosial. Yogyakarta: Pustaka Pelajar.

Cordozo, G. (1997). Manajemen Sumber Daya Manusia. Yogyakarta: Andi Offset.

David, F. R. (2011). Strategic management concepts and cases (13th ed.). Boston: Pearson Education, Inc.

Dwiyanto, A. (2013). Reformasi Birokrasi Publik di Indonesia. Yogyakarta: Universitas Gadjah Mada Press

Dwiyanto, Agus, 2008. Mewujudkan Good Governance Melalui Pelayanan Publik, Yogyakarta: Gadjah Mada University Press.

Dwiyanto, Agustus.,dkk, 2006. Reformasi Birokrasi Publik di Indonesia, Yogyakarta: Gadjah Mada University Press.

Dwiyanto, Agus, 2011. Mengembalikan Kepercayaan Publik Melalui Reformasi Birokrasi, Jakarta : PT Gramedia Pustaka Utama.

Hardiyansyah, 2011, Kualitas Pelayanan Publik, Yogyakarta: Gava Media.

Hasibuan, Malayu S.P, 2003, Organisasi Dan Motivasi, Jakarta: PT Bumi Aksara.

Kumorotomo, Wahyudi dkk. 2009. Governance Reform di Indonesia. Yogyakarta: Gava media dan MAPUGM.
Kurniawan, Agung, 2005, Transformasi Pelayanan Publik, Yogyakarta: Pembaruan.

Handoko, H. (2000). Manajemen Personalia \& Sumber Daya Manusia (2nd ed.). Yogyakarta: Universitas Gadjah Mada.

Luthan, F. (2011). Organizational Behavior An Evidence-Based Approach (12th ed.). New York: McGraw-Hill.

Martoyo, S. (1990). Manajemen Sumber Daya Manusia (5th ed.). Yogyakarta: Yogyakarta, BPFE.

Osbourne, D., \& Plastrik, P. (2010). Memangkas Birokrasi. Jakarta: PPM.

R., M., Steers, R., \& Porter, L. (1997). The Measurement of Organizational Commitment. Journal of Vocational Behaviour.

Sugiyono. (1998). Metode Penelitian Administrasi. Bandung: Alfabeta.

Moenir. 2010. Manajemen Pelayanan Umum Di Indonesia, Jakarta: PT Bumi Askara. Mustafa, Dilly. 2013. Birokrasi Pemerintahan, Bandung: ALFABETA, cv Pasalong, Harbani. 2012. Metode Penelian Administrasi Publik, Bandung: ALFABETA, cv

Sedarmayanti, Hj. 2004. Good Governance (kepemerintahan yang baik), Bandung: ALFABETA, cv 